\title{
Autosomal Recessive Neuromuscular Disorder in a Transgenic Line of Mice
}

\author{
Donna Kelly, ${ }^{1}$ Karen Chancellor, Athena Milatovich, ${ }^{5}$ Uta Francke, ${ }^{5,6}$ Kinuko Suzuki, ${ }^{1,2}$ and Brian Popko ${ }^{1,3,4}$ \\ ${ }^{1}$ Brain and Development Research Center, ${ }^{2}$ Departments of Pathology and ${ }^{3}$ Biochemistry and Biophysics, and ${ }^{4}$ Program \\ in Molecular Biology and Biotechnology, University of North Carolina, Chapel Hill, North Carolina 27599, and ${ }^{5}$ Department \\ of Genetics and ${ }^{6}$ Howard Hughes Medical Institute, Stanford University Medical School, Stanford, California 94305
}

\begin{abstract}
We have generated a line of transgenic mice that when homozygous for the transgene develop a severe, adult-onset neuromuscular disorder. This mutation is likely the result of the insertional inactivation of an endogenous gene by the transgene integration. The mutant mice have a gait abnormality with stiffened and/or splayed hind legs, and adopt a hunched posture with some exhibiting kyphosis of the thoracic spine. These symptoms progress gradually to severe motor dysfunction. Pathologic changes were found in skeletal muscle and peripheral nerve of the mutant animals. In young mice the muscles from both upper and lower extremities show necrosis and phagocytosis. In older mice, regeneration with muscle fiber splitting, internally located nuclei, and variable fiber size are conspicuous features. Interactions between Schwann cells and axons also appear disrupted in these animals. Although many peripheral axons are well myelinated, the nerve and nerve roots contain very large bundles of juxtaposed, bare axons, reminiscent of Schwann cell-axon interactions in early development. Within these bundles there are axons large enough to be myelinated. The relationship between the pathologic changes in the muscles and nerves is not clear. The phenotypic abnormalities of these animals resemble those that occur in the spontaneous mouse mutants dystrophia muscularis and myodystrophy. Nevertheless, the chromosomal position of the transgene integration site, which was mapped by fluorescent in situ hybridization to chromosome 11 , indicates that this disorder represents a new neuromuscular mutation.

[Key words: neuromuscular disorder, transgenic mice, Schwann cell, insertional mutant, muscle degeneration, mouse chromosome 11, BPFD \#36 mutation]
\end{abstract}

\footnotetext{
Received Mar. 19, 1993; revised June 22, 1993; accepted June 29, 1993.

We thank Dr. Ueli Suter and Dr. Eric Shooter for the PMP-22 cDNA clone and Dr. Stanley Froehner and Dr. Thomas Bouldin for critically reviewing the manuscript. We also thank Clarita Langaman for technical assistance and Maria Wagner for photographic assistance. This work was supported in part by National Multiple Sclerosis Society Research Grant RG 2089A1 (B.P.); U.S. Public Health Service Research Grants NS 27336 (B.P.), ES 01104 (B.P. and K.S.), NS 24453 (K.S.), HG 00298 (U.F.); and Mental Retardation Research Center Core Grant HD-031 10, as well as the Howard Hughes Medical Institute, of which U.F. is an investigator. K.C. received support from a Clinical Investigator Development Award CA 01316 from NCI. B.P. is a recipient of a Sloan Neuroscience Research Fellowship, and a NIH Research Career Development Award NS 01637 from NINDS.

Correspondence should be addressed to Brian Popko, Brain and Development Research Center, CB\# 7250; Room 320 BSRC, University of North Carolina, Chapel Hill, NC 27599.

Copyright (C) 1994 Society for Neuroscience $0270-6474 / 94 / 140198-10 \$ 05.00 / 0$
}

During early PNS development, Schwann cells accompany growing neurites into the periphery and segregate the axons into small groups (reviewed in Bray et al., 1981; Webster, 1993). Larger axons are individually myelinated by Schwann cells, whereas groups of smaller axons become embedded, or ensheathed, within the cytoplasmic membrane of a Schwann ccll. Each assembly of Schwann cell and axon is encircled by an envelope of basal lamina, which the Schwann cell produces, within a collagenous endoneurial extracellular matrix (reviewed in Bunge et al., 1986). Interaction with this extracellular matrix appears to be essential for Schwann cells to ensheath and myelinate nerve axons properly.

Myoblasts proliferate during early development of skeletal muscle and fuse to form myotubes. These myotubes subsequently mature into multinucleate myofibers that usually run from tendon to tendon and provide the skeletal muscle's characteristic contractile activity. The interaction of myoblasts with components of the extracellular matrix is an essential event in myogenic differentiation (Menko and Boettiger, 1987), analogous to the requirements for Schwann cell terminal differentiation.

Micc homozygous for the dystrophia muscularis (dy) mutation develop an adult-onset, muscle-degenerative syndrome that is accompanied by abnormalities in Schwann cell-axon interactions (Bradley and Jenkinson, 1973, 1975; Weinberg et al., 1975). Very large bundles of bare axons are found encircled by individual Schwann cells in the dorsal and ventral roots of these mice. The apparent inability of $d y$ Schwann cells to form proper basal lamina has been suggested to contribute to the deficiency of these cells to ensheath axons (Madrid et al., 1975; Cornbrooks et al., 1983). In chimera studies, $d y$ Schwann cells in contact with normal basal lamina produced by wild-type Schwann cells function properly (Peterson and Bray, 1984). Moreover, following recovery from crush injury the basal lamina surrounding $d y$ axons is significantly improved, as are Schwann cell-axon interactions (Stirling, 1975; Bray et al., 1983). The crush injury is thought to provide the $d y$ Schwann cells with a second opportunity to produce proper basal lamina.

The recessive myodystrophy (myd) mouse mutation also results in an adult-onset muscle degenerative syndrome (Lane et al., 1976). Myd mutants resemble $d y$ animals in that very large bundles of juxtaposed bare axons are found in their spinal nerve roots (Rayburn and Peterson, 1978).

We have generated a line of transgenic mice that develop an adult-onset neuromuscular disorder similar to that which occurs in $d y$ and myd animals. The original goal of these studies was 
based on the observation that the regulatory proteins that interact with specific DNA transcriptional control elements are usually present in limiting amounts, and that these proteins can be functionally depleted by transfecting into cells in culture an excess of the specific DNA regulatory molecules (for recent examples, see Chang et al., 1992; Mietus-Snyder et al., 1992). We have attempted to duplicate these transcriptional factor competition studies in transgenic mice by integrating into the mouse genome large concatamers of the DNA control elements of the myelin basic protein (MBP) gene. MBP was chosen as the initial test gene for these studies because the phenotypic consequences of reduced MBP expression have been well characterized (Popko et al., 1987; Readhead et al., 1987; Shine et al., 1992). Nevertheless, the transgenic animals produced, which contained from approximately 6-240 copies of the MBP transcriptional regulatory region incorporated into their genome, all expressed normal MBP mRNA levels.

As mentioned, however, mice from one transgenic line developed an apparently unrelated neuromuscular disorder that is discussed in detail here. Homozygous transgenic animals from this line exhibit progressive postural and gait abnormalities affecting primarily their hind limbs beginning at about 3 months of age. Muscles from these mice show necrosis and regeneration with muscle fiber splitting, internally located nuclei, and variable fiber size. Although many axons are well myelinated in the peripheral nerves of these animals, there are also very large bundles of bare axons partially encircled by individual Schwann cells.

This autosomal recessive neuromuscular disorder is likely the result of the disruption of an endogenous gene due to the transgene integration event. Although the abnormal phenotype exhibited by the transgenic mice discussed here resembles that displayed by $d y$ and myd animals, the transgene array in these mice maps to a chromosomal location distinct from the mutant loci. Therefore, we have generated a new neuromuscular mouse mutant that should provide insight into the molecular and cellular biology of the maintenance of skeletal muscle, as well as Schwann cell-axon interactions.

A preliminary report of these findings has appeared in abstract form (Popko et al., 1992).

\section{Materials and Methods}

DNA for microinjection. Two DNA samples, containing the MBP upstream regulatory region from the mouse MBP cosmid clone cos 138 (Takahashi et al., 1985), were used for the microinjections. For the first sample, a 3.5 kilobase $(\mathrm{kb})$ HindIII fragment containing approximately $1.3 \mathrm{~kb}$ of the upstream region and the MBP first exon was subcloned into pUC12. A $1.3 \mathrm{~kb}$ Smal fragment was then isolated that extends from the pUC12 polylinker to a site 50 nucleotides upstream to the transcription start site of the MBP gene. A similar region has been shown to direct expression of heterologous genes to oligodendrocytes in transgenic mice (Kimura et al., 1989; Turnley et al., 1991; Yoshioka et al., 1991; Hayes et al., 1992). The $1.3 \mathrm{~kb}$ SmaI fragments were incubated with T4 DNA ligase (Bethesda Research Labs, Gaithersburg, MD) to form concatamers and the resulting ligation mixture was used for microinjection.

For the second DNA preparation the $1.3 \mathrm{~kb}$ SmaI fragment described above was subcloned into pBlueScript (Stratagene, La Jolla, CA) and a $1.3 \mathrm{~kb}$ XbaI fragment isolated that is defined by the XbaI sites in the pBlueScript polylinker and the pUC12 polylinker included in the SmaI fragment. The resulting Xbal fragment was essentially the same as the original Smal fragment, differing only by a few nucleotides at the ends. However, the sticky ends of the Xbal fragments ligated more efficiently than the blunt ends of the SmaI fragments when the $1.3 \mathrm{~kb}$ XbaI fragments were ligated to form concatamers. This ligation mixture was fractionated on a $0.4 \%$ agarose gel, and a region containing DNA molecules of approximately $20 \mathrm{~kb}$ and greater was electroeluted into dialysis bags (Maniatis et al., 1982). This preparation contained a higher percentage of large DNA concatamers than the first preparation.

Transgenic mice. Single-cell embryos were isolated from C57Bl/6J $\times$ DBA/2J F1 crosses and microinjected with the DNA concatamers essentially as described (Popko et al., 1989); 174 animals were born from the microinjections. Eleven of these animals were positive for the transgene, and eight produced positive progeny. These transgenic lines are referred to as BPFD (basic protein factor depletion). The eight BPFD lines were bred to homozygosity.

Heterozygous and homozygous animals were identified by slot blot hybridization as described by Francke et al. (1992). Slot blots containing $2.5 \mu \mathrm{g}$ of tail DNA were hybridized with ${ }^{32} \mathrm{P}$-labeled $1.3 \mathrm{~kb}$ MBP upstream fragment. Blots were also hybridized with an actin cDNA to control for the amount of DNA in each slot.

Copy number was determined by quantitative slot blots containing a series of dilutions of transgenic and normal tail DNA samples as described by Francke et al. (1992).

Light and electron microscopy. Mice were perfused through the left cardiac ventricle, under anesthesia, with a mixture of $4 \%$ paraformaldehyde and $2.5 \%$ glutaraldehyde in $0.1 \mathrm{~m}$ phosphate buffer or with $5 \%$ glutaraldehyde in $0.1 \mathrm{M}$ phosphate buffer and then immersed in the same fixative for about $1 \mathrm{hr}$ at room temperature or overnight at $4^{\circ} \mathrm{C}$. Peripheral nerves (sciatic nerve and brachial plexus), spinal roots (L4L5) and skeletal muscles (deltoid, biceps, and gastrocnemius) were dissected, postfixed in $2 \%$ osmium tetroxide, and embedded in epoxy resin in flat molds so that both cross- and longitudinal sections of the same tissues could be obtained for examination. One-micrometer-thick sections of these tissues were cut, stained with toluidine blue, and examined with a light microscope. Selected areas were further processed for electron microscopy. Thin sections for electron microscopy were double stained with uranyl acetate and lead citrate, and examined with a Zeiss $10 \mathrm{~A}$ electron microscope.

Cytogenetics. Fibroblast cultures were generated from six $14 \mathrm{~d} \mathrm{em}-$ bryos produced from a BPFD $\# 36$ heterozygote $\times$ heterozygote mating. Five cultures named BPFD \#36-7a, BPFD \#36-7b, BPFD \#36-7c, BPFD \#36-8a, and BPFD \#36-8b were harvested by standard cytogenetic techniques (20-30 $\min 0.075 \mathrm{M} \mathrm{KCl}$ treatment, followed by fixation by $3: 1$ methanol:glacial acetic acid) using a $4 \mathrm{hr}$ colcemid treatment $(0.5 \mathrm{mg} /$ $\mathrm{ml}$ final concentration) to obtain metaphase chromosomes. Slides were made soon after harvesting.

Fluorescence chromosomal in situ hybridization (FISH) was done using a biotin-11-dUTP nick-translated plasmid, which contained a 3.5 $\mathrm{kb}$ HindIII fragment that spans approximately $1.3 \mathrm{~kb}$ of the upstream region and the first exon of the mouse MBP gene (Takahashi et al., 1985), and a biotin/avidin/fluorescein isothiocyanate detection system. FISH techniques were essentially as described in Milatovich et al. (1991). Hybridization solutions consisted of $0.2-0.4 \mathrm{ng} / \mu \mathrm{l}$ probe DNA, $100 \mathrm{ng} /$ $\mu \mathrm{l}$ salmon sperm DNA as competitor, $50 \%$ formamide, $10 \%$ dextran sulfate, and $1 \times$ saline-sodium citrate (SSC). Slides were hybridized overnight at $37^{\circ} \mathrm{C}$ and washed in three changes of $50 \%$ formamide, $2 \times$ saline-sodium citrate (SSC) at $42^{\circ} \mathrm{C}$ and subsequently washed in three changes of $0.1 \times \mathrm{SSC}$ at $65^{\circ} \mathrm{C}$ or three changes of $2 \times \mathrm{SSC}$ at $42^{\circ} \mathrm{C}$. Slides were counterstained with propidium iodide $(200 \mathrm{ng} / \mathrm{ml}$ final concentration) to visualize the chromosomes. Fluorescent signals were considered specific hybridization only when two signals were seen lying side by side on each chromatid of a particular chromosome. All single signals were assumed to represent random hybridization. Photographs were taken on a Zeiss Axiophot using Ektachrome ASA 400 color slide film. Slides were then destained through an ethanol and methanol series and restained with distamycin A/DAPI $(0.2 \mathrm{mg} / \mathrm{ml}$ and $0.4 \mu \mathrm{g} / \mathrm{ml}$ final concentrations, respectively) as described by Matsuda and Chapman (1991) for chromosome identification.

Nucleic acid isolation, electrophoresis, and hybridization. DNA was isolated from spleen as described by Strauss (1987). DNA samples, 5 $\mu \mathrm{g}$, were digested with appropriate restriction enzymes and electrophoresed through $1 \%$ agarose gels. DNA was transferred to ZetaProbe (BioRad, Melville, NY) membranes overnight in $0.4 \mathrm{~N} \mathrm{NaOH}$ (Reed and Mann, 1985).

RNA was prepared using the guanidine thiocyanate method of Chirgwin et al. (1979). Northern blots were prepared as described (Popko et al., 1987; Stahl et al., 1990).

Probes for hybridizations were ${ }^{32} \mathrm{P}-\mathrm{labeled}$ by either the random priming method of Feinberg and Vogelstein (1983) or the polymerase chain 
Table 1. BPFD transgenic lines

\begin{tabular}{lcll} 
& & & Phenotype $^{b}$ \\
\cline { 3 - 4 } Line \# & Copy \# & Heteroz. & Homoz. \\
\hline 10 & 40 & Norm. & Norm. \\
20 & 50 & Norm. & Norm. \\
30 & 10 & Norm. & Norm. \\
35 & 6 & Norm. & Norm. \\
36 & 120 & Norm. & Muscle Deg. \\
58 & 50 & Norm. & Norm. \\
83 & 50 & Norm. & Norm. \\
150 & 50 & Norm. & Norm. \\
$20 \times 36^{c}$ & 170 & Norm. & ND
\end{tabular}

Copy \# indicates number of copies of $1.3 \mathrm{~kb}$ MBP transcription region integrated into genome of heterozygous animals as determined by quantitative slot blot analysis.

${ }^{\text {"}}$ Phenotype refers to observable phenotype in heterozygous and homozygous offspring.

$20 \times 36$ indicates animals heterozygous for both line 20 and line 36 insertions. " ND, double homozygotes were not generated.

reaction (PCR) method of Jansen and Ledley (1989). Hybridizations and washes were performed as previously described (You et al., 1991).

\section{Results}

Mice with many copies of the MBP transcriptional regulatory region express normal $M B P M R N A$ levels

Microinjection of the concatamers of the MBP gene upstream region produced eight transgenic lines that contained from approximately 6 to as many as 120 copies of the MBP transcriptional regulatory region (Table 1 ). Heterozygous mice from each line were mated to produce homozygous mice, which have twice the number of transgene copies. Heterozygous and homozygous transgenic mice from each BPFD line expressed normal steady state levels of MBP mRNA (data not shown). These data indicate that the presence of multiple copies, as many as 240 , of the MBP transcriptional regulatory region in the mouse genome does not affect the expression of the endogenous MBP gene.

\section{Homozygous BPFD \#36 mice are phenotypically abnormal}

Heterozygous animals from each BPFD line and homozygous mice from all but one line appeared phenotypically normal (Table 1). Homozygous BPFD \#36 mice are generally smaller than heterozygous and wild-type litter mates by $2-3$ weeks of age and begin to display postural abnormalities by $3-4$ months. While all affected mice display stiffening of the hind limbs and some degree of kyphosis of the thoracic spine, there is variation in the posture of affected mice. The hind limbs may be drawn close together, splayed outward in a frog-like stance, or dragged stiffly behind the mouse (Fig. 1). The effect is not always symmetric.

\section{Table 2. BPFD \#36 heterozygote $\times$ heterozygote matings}

\begin{tabular}{lccrc} 
& Female & Male & Total & $\%$ \\
\hline Negative & 38 & 32 & 70 & 27 \\
Heterozygous & 71 & 78 & 149 & 59 \\
Homozygous & 15 & 18 & 33 & 13 \\
Total & 109 & 114 & 223 & \\
\hline
\end{tabular}

The numbers in each category refer to numbers of offspring produced and tested for presence of transgene at weaning from 3 to 4 weeks of age. A total of 223 mice were tested from 37 litters for an average of six pups per litter.

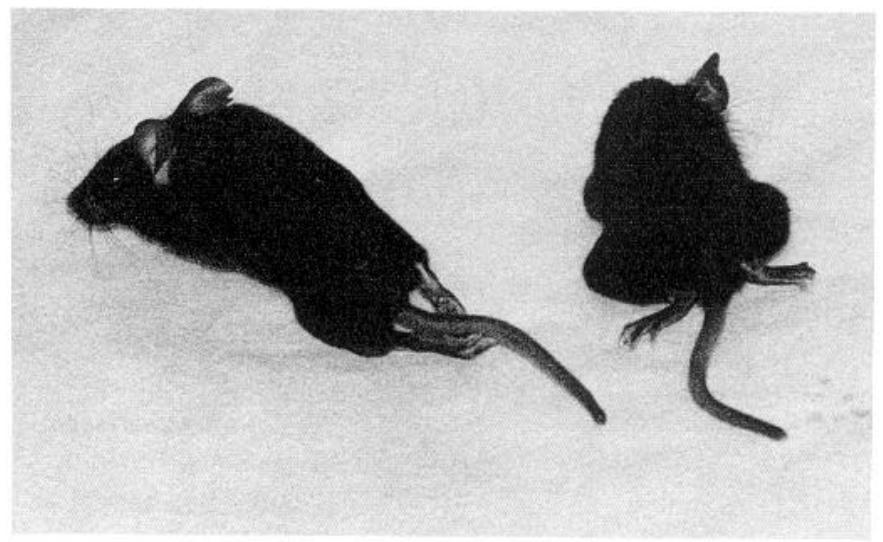

Figure 1. BPFD \#36 Homozygous phenotype. Shown are two 28week-old BPFD \#36 homozygous littermates. The mouse on the left displays the dragging posture with very little mobility in its hind limbs particularly the left hind leg. The mouse on the right displays the more frog-like position of its hind limbs.

In particular, mice with the dragging phenotype often drag only one leg initially while the other moves almost normally. The mice do not switch among postural variations. In the early stages the abnormalities are very mild, but as the animals age their condition worsens and the mice become severely emaciated and have decreased mobility. There is no evidence of tremor or seizures in any of these mice. No homozygote has survived beyond 11 months of age, with most dying between 6 and 8 months of age. The cause of death has not been determined.

Mating performance of homozygotes has been very poor. So far, no successful matings have resulted from crosses of homozygous males to wild-type, heterozygous, or homozygous females. A few litters have been delivered by homozygous females mated to heterozygous males although only one was successfully reared. The females that have become pregnant were young and had not yet developed obvious postural abnormalities.

Although heterozygous mice mate well, the number of homozygotes weaned from heterozygous crosses has only been about half that expected (Table 2). Heterozygous crosses should produce approximately $25 \%$ homozygotes, but of over 200 animals produced from our crosses only about $13 \%$ were homozygous. It is not clear whether the animals are dying in utero, dying shortly after birth prior to weaning, or both. The sexual distribution appears to be normal with equal numbers of males and females produced in each category.

\section{BPFD \#36 mice develop neuromuscular defects}

A morphological examination of homozygous BPFD \#36 animals has revealed pathology in skeletal muscle and peripheral nerve. Skeletal muscles from normal and heterozygous mice show muscle fibers to be polygonal and uniform in size. Nuclei are located at the periphery and only rarely found in the center of muscle fibers (Fig. 2A). In homozygous BPFD \#36 mice, scattered necrotic muscle fibers with or without phagocytosis can be detected as early as 6 weeks of age when clinical symptoms were not yet apparent (Fig. $2 B, C$ ). With age, muscle fibers gradually lost normal polygonal contours and individual fiber size became more variable. In older homozygous mice, muscle fiber splitting and internally placed nuclei in association with increased endomysial fibrous tissue and adipose tissue were very 

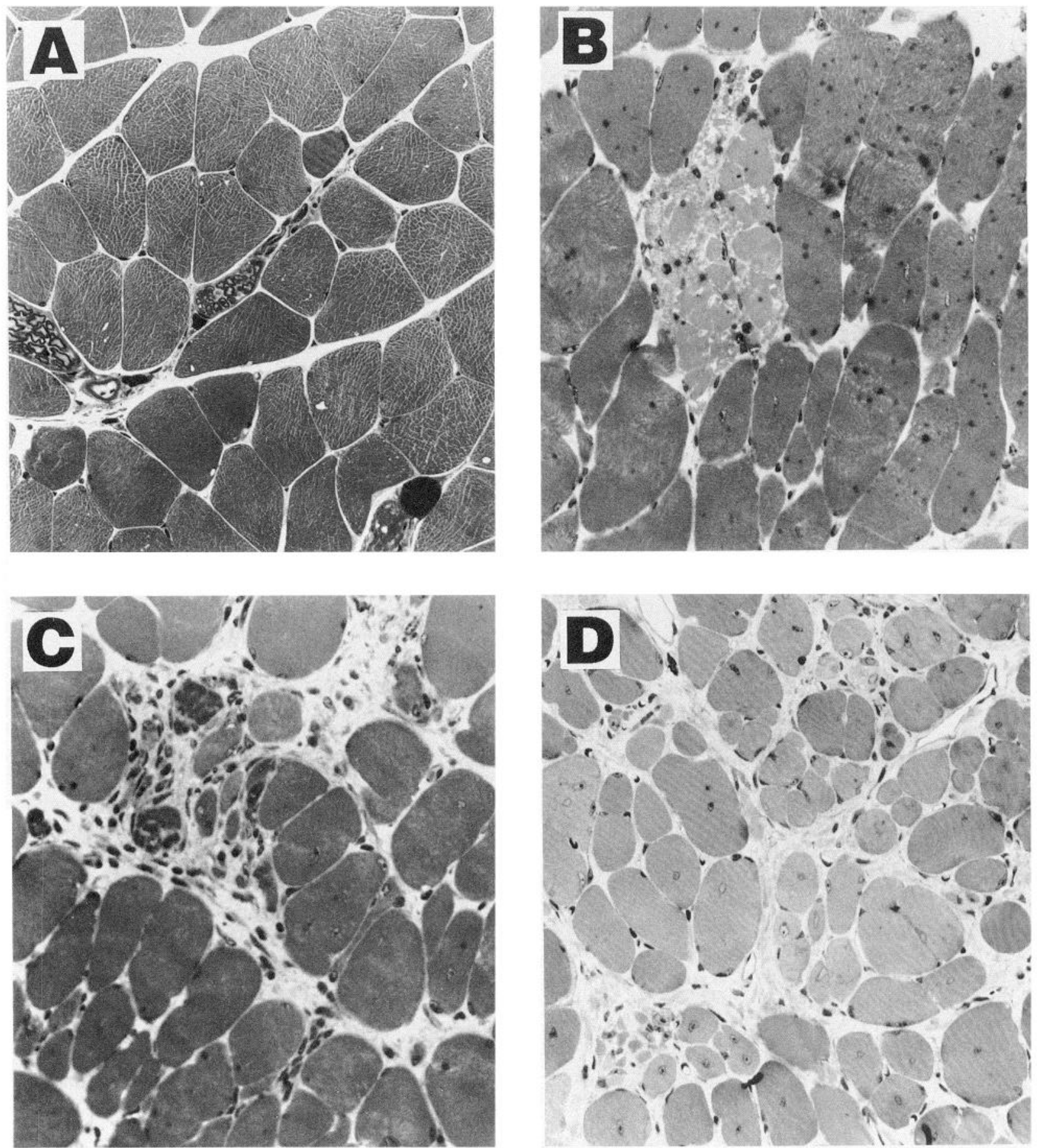

Figure 2. Muscle pathology. A, Gastrocnemius muscle, 34-week-old normal mouse. $B$, Gastrocnemius muscle, 6-week-old homozygous BPFD \#36 mouse. Notice the focus of necrotic muscle fibers and the many centrally located nuclei. $C$, Gastrocnemius muscle, 6 -week-old homozygous BPFD \#36 mouse. Note the phagocytosis of necrotic muscle fibers and variable fiber size. $D$, Psoas muscle section from a 20 -week-old homozygous BPFD \#36 mouse showing increased variability in individual fiber size and endomysial fibrosis. Magnification, $\sim 500 \times$.

conspicuous features (Fig. 2D). Clusters of regenerating fibers containing vesicular nuclei with prominent nucleoli were noted but muscle fiber necrosis and phagocytosis were still recognized. In the muscle of the oldest mice examined (46 weeks old), there were foci of calcification (data not shown).

At the light microscope level, well-defined, poorly stained areas were noted among well myelinated fibers in nerves of homozygous mice (Fig. 3). The number of these areas varied in different nerve bundles but were present in the peripheral nerves and spinal roots. At the ultrastructural level, these areas consisted of large aggregates of closely packed unmyelinated fibers (Fig. 4). Schwann cells were associated with these unmyelinated fibers, but unlike the normal Schwann cell-axon interaction of unmyelinated fibers, the axolemmas of individual fibers made contact with each other due to the absence of intervening Schwann cell cytoplasm (Fig. 5). This Schwann cell-axon interaction re- 

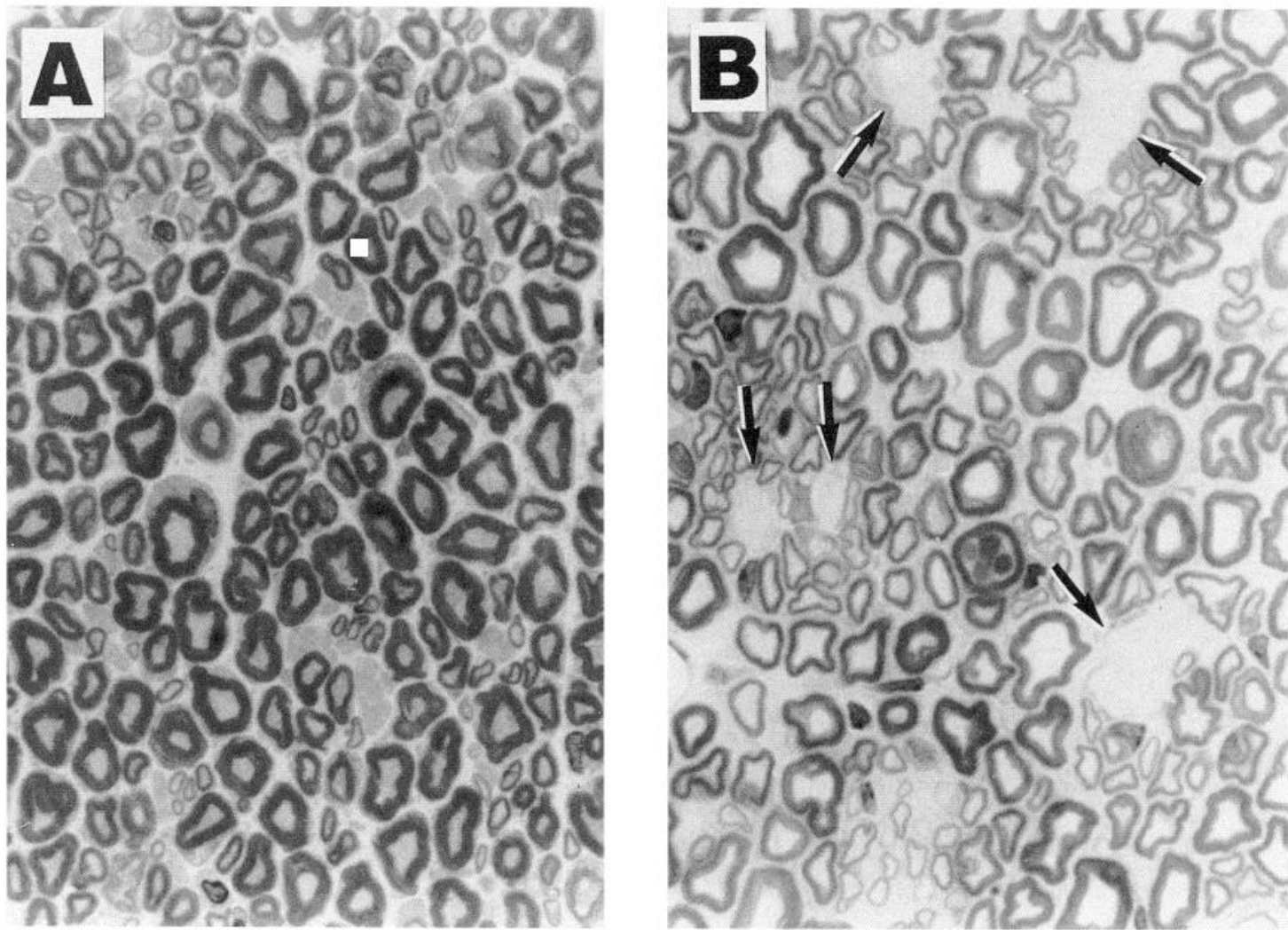

Figure 3. Light microscopy of sciatic nerve. $A$, Sciatic nerve, 6-week-old normal mouse. $B$, Sciatic nerve, 20-week-old homozygous BPFD \#36 mouse. Arrows mark poorly stained areas among many well-myelinated fibers. Magnification, $\sim 750 \times$.

sembles that described in early development of the peripheral nerve (Bray et al., 1981; Webster, 1993). Some unmyelinated axons within these aggregates were large enough to be myelinated. Although uncommon, thinly myelinated axons were found in the periphery of these aggregates of unmyelinated fibers. Normal-appearing basal lamina has been noted surrounding BPFD \#36 Schwann cells (Fig. 5). Unlike changes noted in the muscle, age-related differences could not be substantiated in the peripheral nerves. Myelinated fibers in homozygous mice appeared normal. No unmyelinated fiber aggregates were found in heterozygous or normal mice (data not shown). Moreover, our preliminary light microscopic studies of the CNS of BPFD \#36 homozygotes have not revealed any abnormalities (data not shown).

\section{$B P F D$ \#36 phenotype is likely due to the insertional inactivation of an endogenous gene}

The simplest explanation for the abnormal phenotype observed in BPFD \#36 mice is that the transgene insertion has disrupted the function of a gene critical for normal neuromuscular function. Nevertheless, it is possible that the MBP transcriptional regulatory regions present in BPFD \#36 mice interact with proteins that regulate the expression of other genes. These genes might be more susceptible to subtle decreases in available transcriptional regulatory proteins. The abnormal expression of these genes could possibly lead to the neuromuscular phenotype. To test whether a copy number threshold had been crossed between the phenotypically normal BPFD \#36 heterozygotes ( 120 copies) and affected homozygotes (240 copies), as opposed to an insertional mutagenic event, we produced mice with an intermediate copy number. BPFD \#20 homozygotes (100 copies) and BPFD \#36 heterozygotes were crossed to produce mice heterozygous for both the BPFD \#20 and the BPFD \#36 transgene arrays. The double heterozygotes carry approximately 170 copies of the MBP transcriptional regulatory region (Table 1). These mice appear phenotypically normal and Northern blots showed their level of MBP expression to be normal (data not shown). Therefore, it appears that if the abnormal phenotype observed in BPFD \#36 mice is due solely to the copy number of MBP transcriptional regulatory regions, the minimum number required to produce an abnormal phenotype is somewhere between 170 and 240 copies. More likely, the neuromuscular phenotype in BPFD \#36 mice is due to the insertional disruption by the transgene of an important endogenous gene.

\section{$B P F D$ \#36 phenotype is likely due to a unique mutation}

The phenotype of BPFD \#36 mice is similar to that of two naturally occurring mouse mutants ( $d y$ and $m y d$ ) that develop neuromuscular defects. The myd and $d y$ mutations have been genetically mapped to chromosomes 8 and 10, respectively (Lyon and Searles, 1989). In situ hybridizations were performed to locate the transgene integration site in BPFD \#36 mice to determine if the genetic defect in these animals is related to either the myd or $d y$ mutations. Fluorescent in situ hybridization (FISH) revealed specific hybridization signals in four of the five embryonic cultures examined (Fig. 6). All four cultures were heterozygous for the transgene array. Twenty of the 70 diploid metaphases examined had specific hybridization signals. In all 20 cells, the MBP transgene array was incorporated on only one mouse chromosome 11 at bands B4-B5. These results confirm 


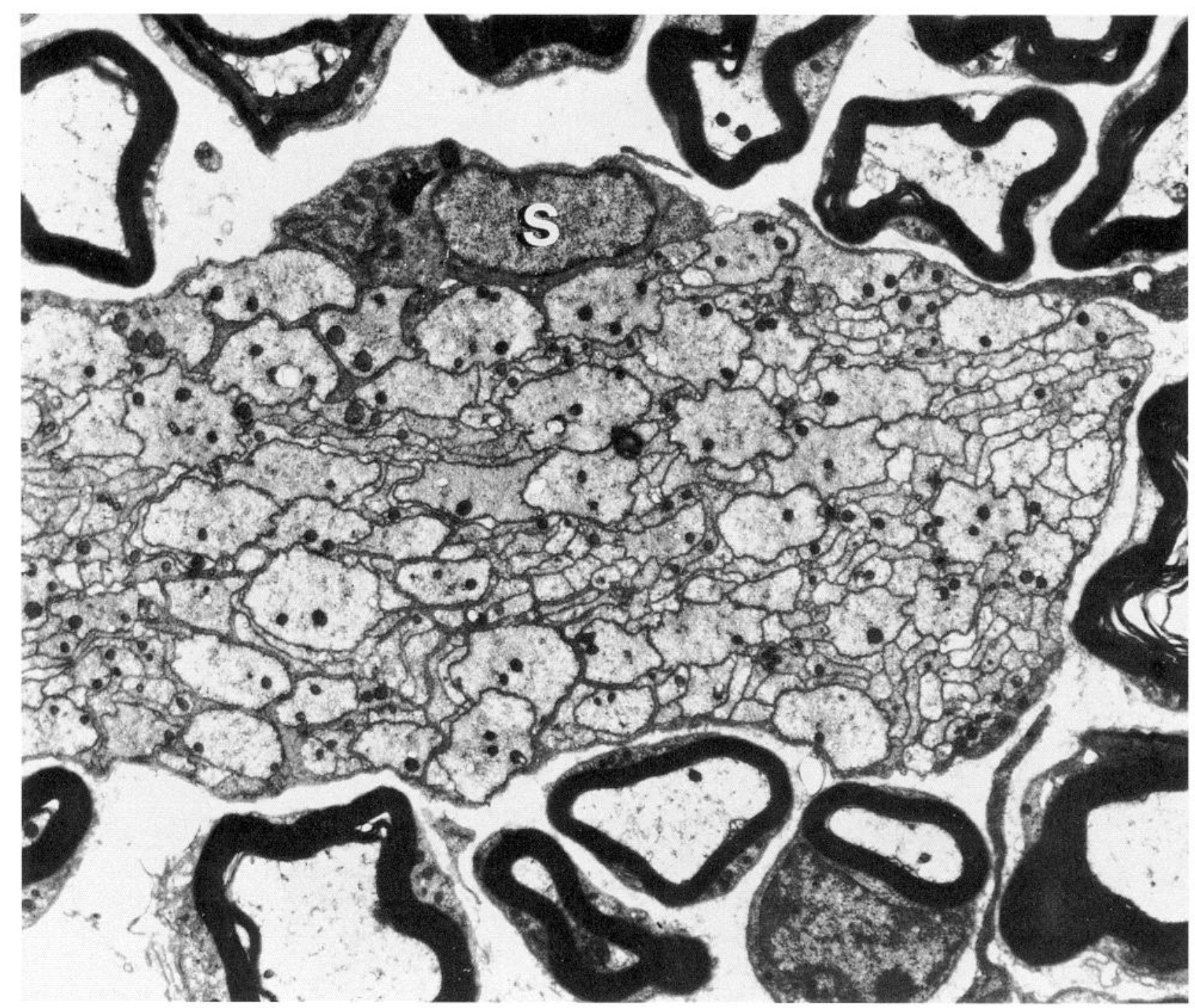

Figure 4. Electron microscopy of sciatic nerve, 20-week-old homozygous BPFD \#36 mouse. Shown is a large aggregate of closely packed unmyelinated fibers associated with Schwann cell $(S)$. Magnification, $\sim 7600 \times$.

the presence of a single integration site for all, or at least most, of the approximately 120 transgene copies, at a position distinct from $d y$ and $m y d$.

In the general vicinity of the insertion site, within the limit of resolution of the FISH technique (Fig. 7), there are four recessive [spasmodic (spd), vibrator $(v b)$, shaker-2 (sh-2), and tipsy $(t i)]$ and one dominant $(T r)$ mutation involving abnormal neuromuscular function or behavior that should be considered (Lane et al., 1987; Lyon and Searles, 1989; Lyon and Kirby, 1993). The molecular defect is only known for Trembler (Tr). Affected $\operatorname{Tr}$ heterozygotes can be identified by tremors and transient seizures, while morphologically the inability of Schwann cells to properly myelinate PNS axons produces an onion bulb neuropathy (Ayers and Anderson, 1973). The $\operatorname{Tr}$ mutation is likely a point mutation in the gene encoding the peripheral myelin protein PMP-22 (Suter et al., 1992a,b). Furthermore, the dominant human disorders Charcot-Marie-Tooth disease type 1A (CMT1A) and hereditary neuropathy with liability to pressure palsies (HNPP) map to the region of human chromosome 17 that is homologous with the region of mouse chromosome 11 containing the $\operatorname{Tr}$ mutation. CMT1A and HNPP result in demyelination, as well as muscle weakness and atrophy, and are thought to be due to abnormalities associated with the PMP-22 gene (Patel et al., 1992; Valentijn et al., 1992; Chance et al., 1993; Suter et al., 1993). Although the phenotype of BPFD \#36 mice is distinct from the abnormal morphology associated with the $\operatorname{Tr}$ mutation, the BPFD \#36 integration site is relatively near the PMP-22 locus, and may have caused a disruption distinct from that caused by the point mutation that leads to the $\operatorname{Tr}$ phenotype, thus resulting in a unique phenotype. Hybridization of Southern blots with radiolabeled PMP-22 cDNA detected no polymorphisms between wild-type mice and BPFD \#36 transgenic mice, suggesting that the BPFD \#36 transgene did not cause any major disruption of the PMP-22 gene (Fig. $8 A$ ). Moreover, Northern blot analysis of sciatic nerve RNA did not detect any difference in PMP-22 mRNA levels (Fig. $8 B$ ). Therefore, it appears that the BPFD \#36 phenotype is not related to PMP-22 expression or the $\operatorname{Tr}$ mutation.

\section{Discussion}

In our unsuccessful effort to reduce the transcriptional activity of the MBP gene in vivo through a transcriptional competition 


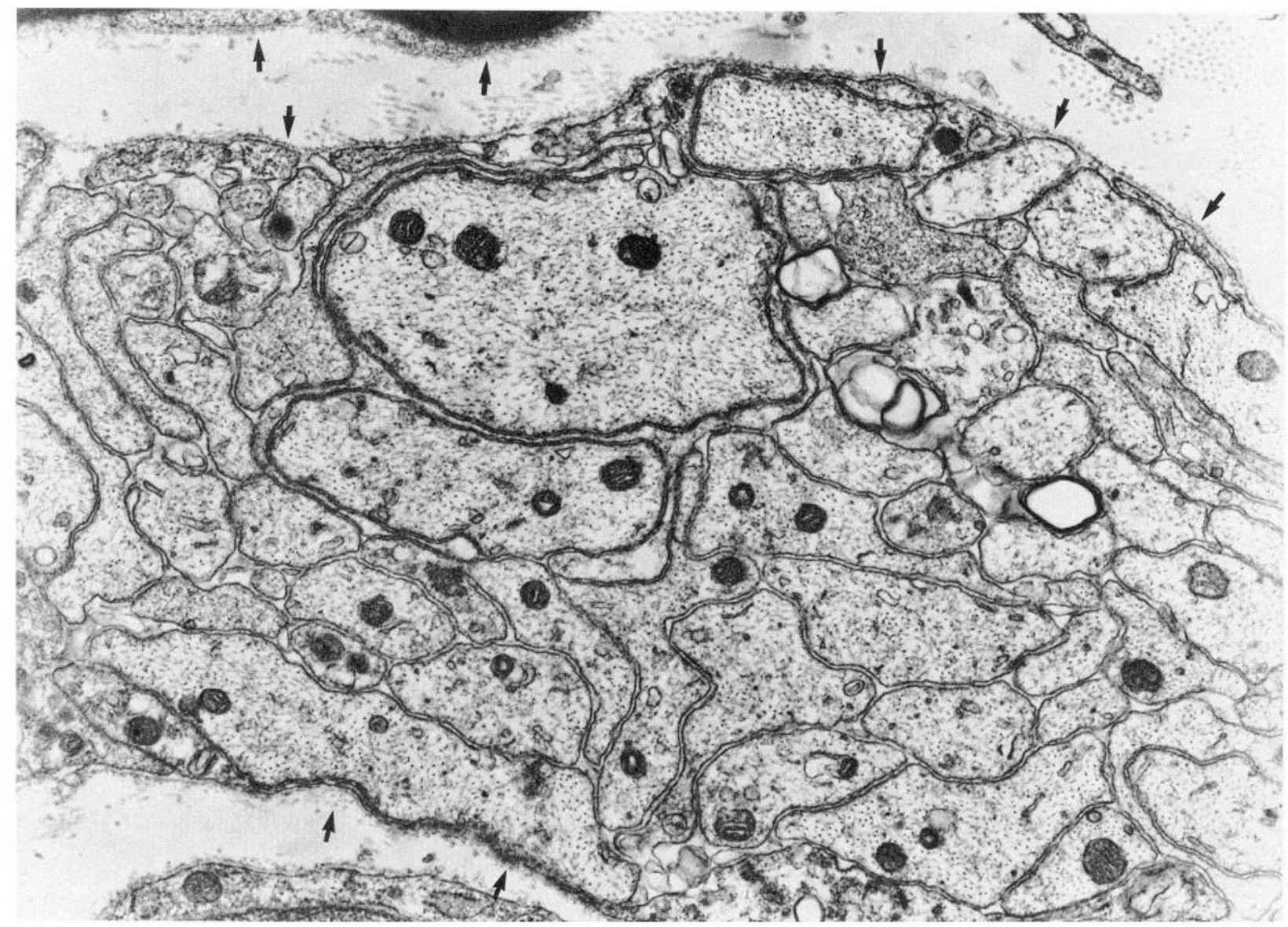

Figure 5. Electron microscopy of sciatic nerve, 15-week-old homozygous BPFD \#36 mouse. Shown is a group of unmyelinated axons, some of which are very large, surrounded by Schwann cell basal lamina (arrows). Axons are in close contact with each other without intervening Schwann cell cytoplasm. Magnification, $\sim 26,000 \times$.

approach, we have produced a mutant line of transgenic mice that develop a neuromuscular disorder. Homozygous animals from line BPFD \#36 develop an adult-onset neuromyopathy.

The molecular origin of the abnormal phenotype that develops in homozygous BPFD \#36 mice is not certain. These mice contain approximately 240 copies of the MBP transcriptional regulatory region incorporated into their genome, the highest copy number of any of the BPFD animals. Possibly, the regulatory proteins that bind to the MBP transcriptional control region are also responsible for the regulation of other genes. These regulatory proteins may be functionally depleted in BPFD \#36 mice to the extent that they are incapable of properly controlling these other genes, but are present in sufficient quantities to regulate accurately MBP transcription. If this were the case, the abnormal phenotype of BPFD \#36 animals could be the result of the inappropriate expression of these other genes, due to the functional reduction of transcriptional factors. Nevertheless, BPFD \#36 mice express normal levels of the predominant PNS and CNS myelin protein genes, which are coordinately regulated with MBP during the myelination process and would seem like logical targets for common transcriptional regulatory proteins (D. Kelly and B. Popko, unpublished observations). Furthermore, it seems unlikely that the functional depletion of transcriptional factors would result in such a sharp threshold between the completely normal phenotype of BPFD \#36 heterozygotes (120 copies) and the abnormal phenotype of ho- mozygotes (240 copies). We have also generated compound transgene heterozygotes between BPFD \#20 (50 copies) and BPFD \#36 (120 copies) animals that contain approximately 170 copies of the MBP transcriptional regulatory region. These animals appear completely normal, suggesting that the copy number threshold between a normal or an abnormal phenotype would have to be quite small.

We believe the neuromuscular disorder that BPFD \#36 animals experience is the result of the insertional inactivation of an important endogenous gene by the transgene integration event. About $5-10 \%$ of all transgene insertions are believed to result in such gene inactivations (Palmiter and Brinster, 1986; Costantini et al., 1989; Gridley et al., 1991; Meisler, 1992). A number of interesting mouse mutants have resulted from the disruption of endogenous loci by transgenes. One advantage of such mutants is that the transgene can be used as a molecular tag in the isolation of the disrupted gene. This approach has been used to isolate the transgene-disrupted genes responsible for the $\operatorname{limb}$ deformity, legless, and H $\beta 58$ mutations (Woychik et al., 1990; Singh et al., 1991; Lee et al., 1992; Vogt et al., 1992). Nevertheless, our initial efforts toward the identification of the defective gene in BPFD \#36 mice suggest that the organization of the transgene array in these animals is complex (Kelly and Popko, unpublished observations). There appear to be islands of genomic DNA, of unknown origin, within the large concatamer of MBP transcriptional regulatory regions. A gross chromosom- 

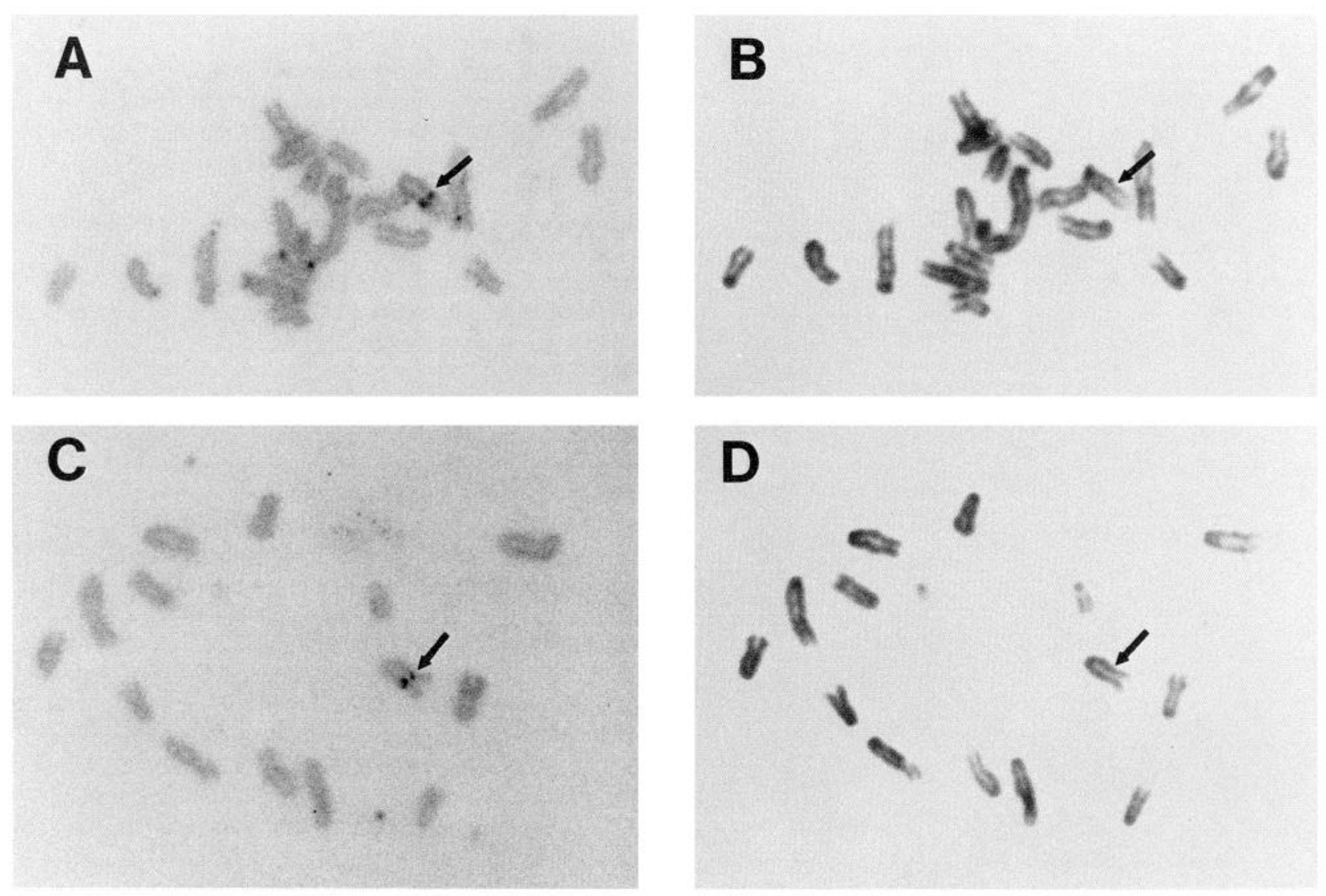

Figure 6. Fluorescence in situ hybridization (FISH): representative metaphases from the FISH experiment with biotin-11-dUTP-labeled plasmid containing a $3.3 \mathrm{~kb}$ cDNA insert that codes for mouse MBP hybridized to fibroblast chromosomes from BPFD \#36 transgenic mice. $A$ and $C$ show one mouse chromosome with specific hybridization of the MBP plasmid (arrows). Chromosomes were counterstained with propidium iodide. $B$ and $D$ show the same two metaphases destained and restained with DAPI to identify the labeled chromosome. The MBP plasmid hybridized to one mouse chromosome 11 at bands B4-B5.

\section{Homologous Loci}

in Humans

HSA22

HSA7

HSA2

HSA16

HSA5

HSA4

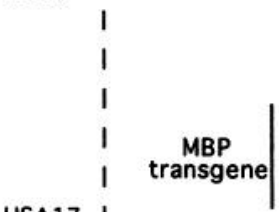

HSA17 I

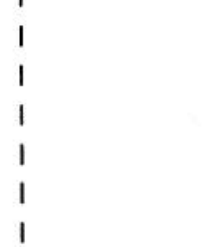

Loci with Cytogenetic Locations

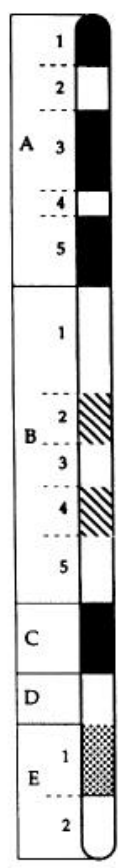

MMU11

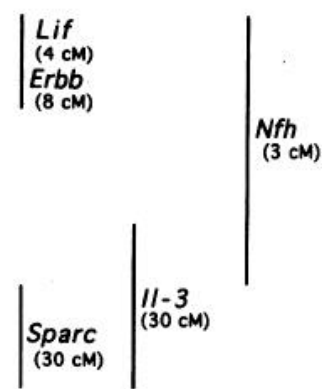

\section{Neurologic Loci on}

Linkage Map

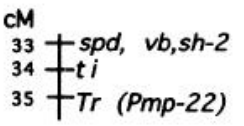

Figure 7. Ideogram of mouse chromosome 11. To the left of the ideogram, the solid line indicates our localization of the MBP transgene by FISH to bands B4-B5 of mouse chromosome 11. The human chromosomes that contain homologous loci are listed on the left, with a broken line indicating the region of mouse chromosome 11 that is syntenically conserved on human chromosome 17. To the right of the ideogram, solid lines indicate the murine loci with cytogenetic locations determined by chromosomal in situ hybridization. Their positions on the linkage map are indicated in parentheses (with $N D=$ not done). On the far right a partial linkage map shows the mouse neurological mutations in the vicinity of the transgene integration site. 


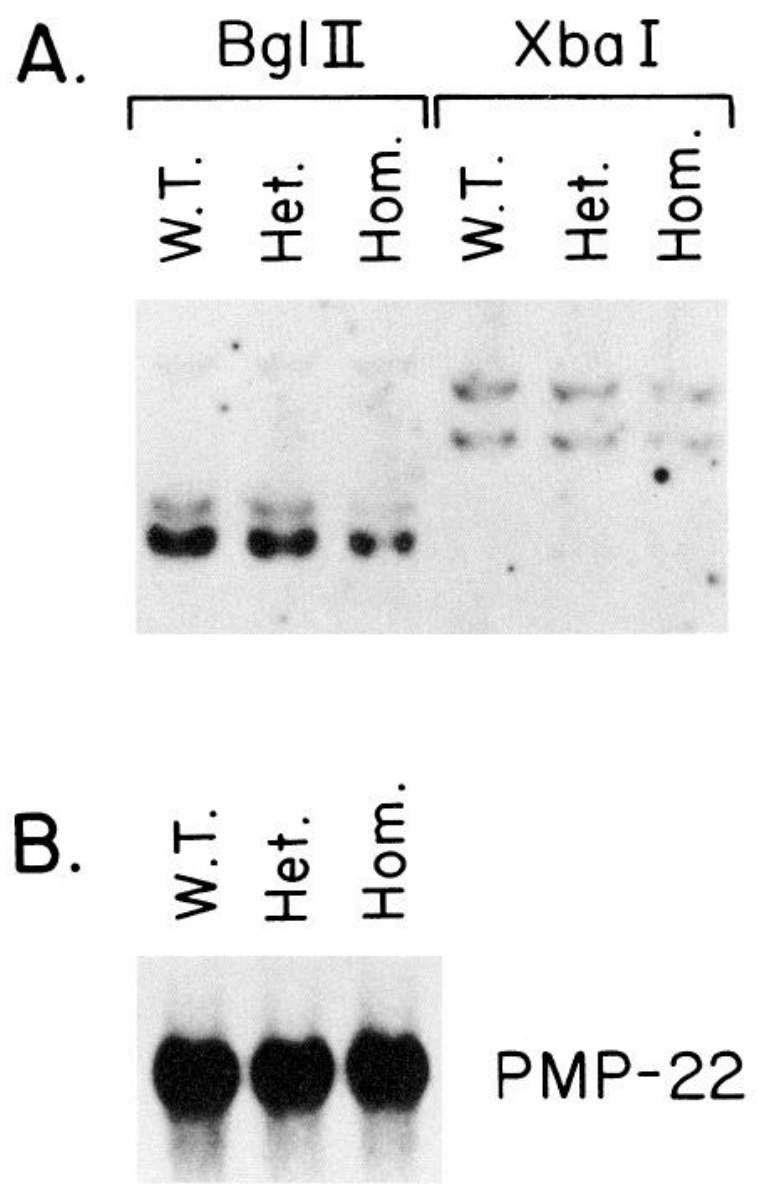

Figure 8. No effect of BPFD \#36 insertion on PMP-22. A, Approximately $5 \mu \mathrm{g}$ aliquots of DNA from C57Bl (W.T.), BPFD \#36 heterozygote (Het.), and homozygote $(\mathrm{Hom}$.) mice were digested with BglII and XbaI, separated on a $1 \%$ agarose gel, transferred to nylon membrane, and hybridized to radiolabeled PMP-22 probe. $B$, Approximately $2.5 \mu \mathrm{g}$ of total RNA from pools of sciatic nerves was separated on a $1 \%$ denaturing gel, transferred to nylon, and hybridized with radiolabeled PMP-22 probe. W.T., BPFD \#36 normal littermates (seven mice); Het., BPFD \#36 heterozygotes (six mice); Hom., BPFD \#36 homozygotes (six mice).

al rearrangement was not seen in our cytogenetic analyses, although a submicroscopic rearrangement of chromosome 11 near the integration site cannot be excluded. The complexity of this region will likely hinder our efforts toward the identification of the disrupted gene.

The $B P F D$ \#36 mutation results in muscle and nerve abnormalities that are very similar to those observed in two naturally occurring autosomal recessive mouse mutants myd and $d y$. Nevertheless, this mutation is not allelic to either myd or $d y$. The transgene integration site in BPFD \#36 animals maps to chromosome 11 , whereas the $m y d$ and $d y$ loci have been genetically mapped to chromosomes 8 and 10 , respectively. Furthermore, only normal progeny result when heterozygous BPFD \#36 mice are bred with heterozygous $d y$ animals (Kelly and Popko, unpublished observations).

The region of chromosome 11 that contains the transgene array in BPFD \#36 animals contains several mutations that result in neurological defects (Lane et al., 1987; Lyon and Searles, 1989). Trembler, a dominant mutation in the myelin protein gene PMP-22, results in poorly myelinated PNS axons. The organization and expression of the PMP-22 gene, however, appear unaltered in BPFD \#36 mice. The defective genes responsible for the recessive mutations spasmodic (spd), vibrator ( vi), shaker-2 (sh-2), and tipsy (ti), which are also located in the general vicinity of the BPFD \#36 integration site, have not been identified. Although the neurological defects that result from these mutations are distinct from the peripheral nerve abnormality that occurs in BPFD \#36 mice, phenotype can vary greatly depending on type of mutation and strain variation. Therefore, a possible link between these mutations and the BPFD \#36 mutation needs to be explored.

The relationship between the muscle and nerve abnormalities that develop in BPFD \#36 mice is unclear. At the earliest time point examined, 6 weeks, muscle and nerve pathology are apparent. Possibly, the transgene integration event disrupted multiple genes resulting in independent disorders of muscle and nerve. This seems unlikely in that the independent mutations $d y$ and myd result in similar neuromyopathies. Another possibility is that the $B P F D \# 36$ mutation is in a gene that plays an important role in both tissues. Alternatively, the $B P F D \# 36$ mutation may primarily affect either muscle or nerve, and the abnormality seen in the other tissue is a consequence of the primary event. This issue will likely be resolved upon the further morphological characterization of muscle and nerve from these mice, as well as the isolation of the disrupted BPFD \#36 gene.

In summary, we have generated a mutant line of transgenic mice that develop a severe, adult-onset neuromuscular disorder. This autosomal recessive mutation is likely the result of the insertional inactivation of an endogenous gene by the transgene. These animals provide an excellent model system for the study of human neuromyopathies. The muscle pathology that develops in these mice closely resembles that which occurs in human primary myopathies (i.e., Duchenne muscular dystrophy). Moreover, the nerve abnormalities present in these animals should further our understanding of normal Schwann cell-axon interactions. The BPFD \#36 mice are available upon request.

\section{References}

Ayers MM, Anderson RM (1973) Onion bulb neuropathy in the Trembler mouse: a model of hypertrophic interstitial neuropathy (DejerineSottas) in man. Acta Neuropathol (Berl) 25:54-70.

Bradley WG, Jenkinson M (1973) Abnormalities of peripheral nerves in murine muscular dystrophy. J Neurol Sci 18:227-247.

Bradley WG, Jenkinson M (1975) Neural abnormalities in the dystrophic mouse. J Neurol Sci 25:249-255.

Bray GM, Rasminsky M, Aguayo AJ (1981) Interactions between axons and their sheath cells. Annu Rev Neurosci 4:127-162.

Bray GM, David S, Carlstedt T, Aguayo AJ (1983) Effects of crush injury on the abnormalities in the spinal roots and peripheral nerves of dystrophic mice. Muscle Nerve 6:497-503.

Bunge RP, Bunge MB, Eldridge CF (1986) Linkage between axonal ensheathment and basal lamina production by Schwann cells. Annu Rev Neurosci 9:305-328.

Chance PF, Alderson MK, Leppig KA, Lensch MW, Matsunami N, Smith B, Swanson PD, Odelberg SJ, Disteche CM, Bird TD (1993) DNA deletion associated with hereditary neuropathy with liability to pressure palsies. Cell 72:143-151.

Chang LA, Smith T, Pognonec P, Roeder RG, Murialdo H (1992) Identification of USF as the ubiquitous murine factor that binds to and stimulates transcription from the immunoglobulin lambda 2-chain promoter. Nucleic Acids Res 20:287-293.

Chirgwin JM, Przybyla AE, MacDonald RJ, Rutter WJ (1979) Isolation of biologically active ribonucleic acid from sources enriched in ribonuclease. Biochemistry 18:5294-5299.

Cornbrooks CJ, Mithen F, Cochran JM, Bunge RP (1983) Factors affecting Schwann cell basal lamina formation in cultures of dorsal 
root ganglia from mice with muscular dystrophy. Brain Res Dev Brain Res 6:57-67.

Costantini F, Radice G, Lee JJ, Chada KK, Perry W, Son HJ (1989) Insertional mutations in transgenic mice. Prog Nucleic Acid Res Mol Biol 36:159-169.

Feinberg A, Volgelstein B (1983) A technique for radiolabeling DNA restriction endonuclease fragments to high specific activity. Anal Biochem 132:6-13.

Francke U, Hsieh C-L, Kelly DJ, Lai E, Popko BJ (1992) Induced reciprocal translocation in transgenic mice near sites of transgene integration. Mamm Genome 3:209-216.

Gridley $T$ (1991) Insertional versus targeted mutagenesis in mice. New Biol 3:1025-1034.

Hayes C, Kelly D, Murayama S, Komiyama A, Suzuki K, Popko B (1992) Expression of the Neu oncogene under the transcriptional control of the myelin basic protein gene in transgenic mice: generation of transformed glial cells. J Neurosci Res 31:175-187.

Jansen R, Ledley FD (1989) Production of discrete high specific activity DNA probes using the polymerase chain reaction. Genet Anal Tech Appl 6:79-83.

Kimura M, Sato M, Akatsuka A, Nozawa-Kimura S, Takahashi R, Yokoyama M, Nomura T, Katsuki M (1989) Restoration of myelin formation by a single type of myelin basic protein in transgenic shiverer mice. Proc Natl Acad Sci USA 86:5661-5665.

Lane PW, Beamer TC, Myers DD (1976) Myodystrophy, a new myopathy on chromosome 8 of the mouse. J Ilered 67:135-138.

Lane PW, Ganser AL, Kerner A-L, White WF (1987) Spasmodic, a mutation on chromosome 11 in the mouse. $J$ Hered 78:353-356.

Lee JJ, Radice G, Perkins CP, Costantini F (1992) Identification and characterization of a novel, evolutionarily conserved gene disrupted by the murine $H \beta 58$ embryonic lethal transgene insertion. Development 115:277-288.

Lyon MF, Kirby MC (1993) Mouse chromosome atlas. Mouse Genome 91:40-80.

Lyon MF, Searles AG (1989) Genetic variants and strains of the laboratory mouse, $2 \mathrm{~d}$ ed. New York: Oxford UP.

Madrid RE, Jaros E, Cullen MJ, Bradley WG (1975) Genetically determined defect of Schwann cell basement membrane in dystrophic mouse. Nature 257:319-321.

Maniatis T, Fritsch EF, Sambrook J (1982) Molecular cloning: a laboratory manual, pp 164-165. Cold Spring Harbor, NY: Cold Spring Harbor Laboratory.

Matsuda Y, Chapman VM (1991) In situ analysis of centromeric satellite DNA segregating in Mus species crosses. Mamm Genome 1:71-77.

Meisler MH (1992) Insertional mutation of 'classical' and novel genes in transgenic mice. Trends Genet 8:341-344.

Menko AS, Boettiger D (1987) Occupation of the extracellular matrix receptor, integrin, is a control point for myogenic differentiation. Cell 51:51-57.

Mietus-Snyder M, Sladek FM, Ginsburg GS, Kuo CF, Ladias JA, Darnell JE Jr, Karathanasis SK (1992) Antagonism between apolipoprotein AI regulatory protein 1, Ear3/COUP-TF, and hepatocyte nuclear factor 4 modulates apolipoprotein CIII gene expression in liver and intestinal cells. Mol Cell Biol 12:1708-1718.

Milatovich A, Travis A, Grosschedl R, Francke U (1991) Gene for lymphoid enhancer-binding factor (LEF1) mapped to human chromosome 4(q23-q25) and mouse chromosome 3 near Egf. Genomics 11:1040-1048.

Palmiter RD, Brinster RL (1986) Germ-line transformation of mice. Annu Rev Genet 20:465-499.

Patel PI, Roa BB, Welcher AA, Schoener-Scott R, Trask BJ, Pentao L, Snipes GJ, Garcia CA, Francke U, Shooter EM, Lupski JR, Suter U (1992) The gene for the peripheral myelin protein PMP-22 is a candidate for Charcot-Marie-Tooth disease type 1A. Nature Genet 1:159165.

Peterson AC, Bray GM (1984) Normal basal laminas are realized on dystrophic Schwann cells in Dystrophic-Shiverer chimera nerves. J Cell Biol 99:1831-1837.

Popko B, Puckett C, Lai E, Shine HD, Readhead C, Takahashi N, Hunt SW III, Sidman RL, Hood L (1987) Myelin deficient mice: expression of myelin basic protein and generation of mice with varying levels of myelin. Cell 48:713-721.

Popko B, Readhead C, Dausman J, Hood L (1989) Transgenic mice in neurobiological research. In: Neuromethods, Vol 16 (Boultan AA, Baker GB, Campagnoni A, eds), pp 221-237. Clifton, NJ: Humana.

Popko B, Kelly D, Milatovich A, Francke U, Suzuki K (1992) Severe adult-onset neuromuscular disorder in a transgenic line of mice. Soc Neurosci Abstr 18:452.2.

Rayburn HB, Peterson AC (1978) Naked axons in myodystrophic mice. Brain Res 146:380-384.

Readhead C, Popko B, Takahashi N, Shine HD, Saavedra RA, Sidman RL, Hood L (1987) Expression of a myelin basic protein gene in transgenic shiverer mice: correction of the dysmyelinating phenotype. Cell 48:703-712.

Reed KC, Mann DA (1985) Rapid transfer of DNA from agarose gels to nylon membranes. Nucleic Acids Res 13:7207-7221.

Shine HD, Readhead C, Popko B, Hood L, Sidman RL (1992) Morphometric analysis of normal, mutant, and transgenic CNS: correlation of myelin basic protein expression to myelinogenesis. J Neurochem 58:342-349.

Singh G, Supp DM, Schreiner C, McNeish J, Merker H-J, Copeland NG, Jenkins NA, Potter SS, Scott W (1991) Legless insertional mutation: morphological, molecular, and genetic characterization. Genes Dev 5:2245-2255.

Stahl N, Harry J, Popko B (1990) Quantitative analysis of myelin protein gene expression during development in the rat sciatic nerve. Brain Res Mol Brain Res 8:209-212.

Stirling CA (1975) Experimentally induced myelination of amyelinated axons in dystrophic mice. Brain Res 87:130-135.

Strauss WM (1987) Preparation of genomic DNA from mammalian tissue. In: Current protocols in molecular biology (Ausubel FM, R Brent, RE Kingston, DD Moore, JG Seidman, JA Smith, K Struhl, eds), pp 2.2.1-2.2.3. New York: Wiley Interscience.

Suter U, Welcher AA, Ozcelik T, Snipes GJ, Kosaras B, Francke U, Billings-Gagliardi S, Sidman RL, Shooter EM (1992a) Trembler mouse carries a point mutation in a myelin gene. Nature 356:241244.

Suter U, Moskow JJ, Welcher AA, Snipes GJ, Kosaras B, Sidman RL, Buchberg AM, Shooter EM (1992b) A leucine-to-proline mutation in the putative first transmembrane domain of the 22-kDa peripheral myelin protein in the Trembler- $J$ mouse. Proc Natl Acad Sci USA 89:4382-4386.

Suter U, Welcher AA, Snipes GJ (1993) Progress in the molecular understanding of hereditary peripheral neuropathies reveals new insights into the biology of the peripheral nervous system. Trends Neurosci 16:50-56.

Takahashi N, Roach A, Teplow DB, Prusiner SB, Hood LE (1985) Cloning and characterization of the myelin basic protein gene from mouse: one gene can encode both $14 \mathrm{kd}$ and $18.5 \mathrm{kd}$ MBPs by alternate use of exons. Cell 42:139-148.

Turnley AM, Morahan G, Okano H, Bernard O, Mikoshiba K, Allison J, Bartlett PF, Miller JFAP (1991) Dysmyelination in transgenic mice resulting from expression of class 1 histocompatibility molecules in oligodendrocytes. Nature 353:566-569.

Valentijn LJ, Baas F, Wolterman RA, Hoogendijk JE, van den Bosch NHA, Zorn I, Gabreels-Festen AAWM, de Visser M, Bolhuis PA (1992) Identical point mutations of PMP-22 in Trembler-J mouse and Charcot-Marie-Tooth disease type 1A. Nature Genet 2:288-291.

Vogt TF, Jackson-Grusby L, Wynshaw-Boris AJ, Chan DC, Leder P (1992) The same genomic region is disrupted in two transgene-induced limb deformity alleles. Mamm Genome 3:431-437.

Webster HD (1993) Development of peripheral nerve fibers. In: Peripheral neuropathy, Vol 1,3d ed (Dyck PJ, Thomas PK, Griffin JW, Low PA, Poduslo JF, eds), pp 243-266. Philadelphia: Saunders.

Weinberg HJ, Spencer PS, Raine CS (1975) Aberrant PNS development in dystrophic mice. Brain Res 88:532-537.

Woychik RP, Maas RL, Zeller R, Vogt TF, Leder P (1990) 'Formins': proteins deduced from the alternative transcripts of the limb deformity' gene. Nature 346:850-853.

Yoshioka T, Feigenbaum L, Jay G (1991) Transgenic mouse model for central nervous system demyelination. Mol Cell Biol 11:54795486.

You K-H, Hsieh C-L, Hayes C, Stahl N, Francke U, Popko B (1991) DNA sequence, genomic organization, and chromosomal localization of the mouse peripheral myelin protein zero gene: identification of polymorphic alleles. Genomics 9:751-757. 